\title{
Influence of Grid Presence in the Characteristics of Applied Mortars
}

\author{
Isabel Torres ${ }^{1}$, Inês F. Colen ${ }^{2}$, Dora Silveira ${ }^{3}$ and Rafael T. Pinto ${ }^{4}$ \\ ${ }^{1}$ DECivil, University of Coimbra/ADAI-LAETA/Itecons, itorres@dec.uc.pt \\ ${ }^{2}$ CERIS, DECivil, IST, University of Lisbon, ines.flores.colen@tecnico.ulisboa.pt \\ ${ }^{3}$ Itecons, dora.silveira@itecons.uc.pt \\ ${ }^{4} \mathrm{PhD}$ student, DECivil, University of Coimbra, Research fellow, IST, rafaeltravincas@gmail.com
}

\begin{abstract}
The most commonly used wall coverings are still, undoubtedly, plasters and renders, whether lime-based or cement-based, whether traditional and prepared in-situ or pre-dosed. In accordance with the available standards, the characterization of these mortars is made on laboratory test specimens, with dimensions, curing conditions and test procedures according to the prescribed. However, when applying these mortars to the real substrates, their behaviour will not be the same. After application of the mortar to the substrate, an interface will be formed, and the interactions that occur after the contact of the mortar, still in the plastic state, with the substrate will change over time due to the hydration kinetics and absorption of the substrate. It is very important to know the real behaviour of mortars after application, in order to ensure their durability. A research project is being developed to analyse the proper behaviour of mortars after application to the substrates. In order to characterize a mortar after application to a substrate, it is necessary to detach it. The introduction of a fiberglass grid in the mortarsubstrate interface makes the detachment easier. The purpose of this study is to determine if the placement of this grid will influence the characteristics of the applied mortar. For this, an experimental campaign was carried out, comparing the characteristics of two mortar formulations, applied to different types of substrate (without introduction of the fiberglass grid), with the characteristics of these mortars applied to the same substrates, but with the introduction of a fiberglass grid at the interface mortar-substrate. In this paper, we present the results obtained for some of the physical and mechanical characteristics of cement and hydraulic lime mortars.
\end{abstract}

Keywords: Mortars, Substrates, Interface, Durability, Fiberglass Grid.

\section{Introduction}

Mortar based coverings are widely used in all types of constructions, whether new or old, in need of rehabilitation or requalification. When we talk about exterior coverings, we are talking about the outermost layer of protection of these constructions, i.e. the layer that will contribute most strongly to their durability. There is an increasing variety of available solutions, and it is very important to ensure the quality of the applied mortars, since they must contribute to the habitability, comfort and durability of buildings. In recent years, much research has been conducted to increase knowledge on the behaviour of different types of mortars and to develop new formulations incorporating new products, so that one can always make the best choices, regarding the type of mortar to be used, its composition and characteristics.

The choice of the mortar that is best suited to the real situation is based on its various properties, which are determined in laboratory, following all applicable standards, particularly with respect to the dimensions of the test specimens, curing conditions and test methodology.

After the mortar has been selected, it is applied to the real substrate - and there are various 
types of substrates, such as hollow brick, solid brick, pre-cast concrete, concrete blocks, natural stone, among others. It is known that inter-layer adhesion is one of the key performance indicators of multi-layer systems. The behaviour of mortars depends on the adhesion between the substrate and the mortar itself. This is one of the characteristics that will influence the properties and behaviour of the mortar (Moropoulou et al., 2000).

When applying a mortar to a real substrate, which will always have some porosity - unlike the laboratory moulds where the specimens that are used to characterize mortars are made, which have virtually no porosity - , an interaction will occur between the two surfaces. The contact between these two elements occurs with the mortar still in the plastic state. When this contact occurs, part of the mixing water, containing dissolved components of the binder, is absorbed by the substrate and penetrates its pores and/or discontinuities. Inside the pores of the substrate, hydration phenomena of cement/lime occur. After this penetration into the substrate and during the subsequent mortar hardening phases, the mortar is subjected to real climatic conditions, which may be quite different from the curing conditions recommended by the mortar characterization standards.

From the foregoing, it can be concluded that the same mortar moulded into specimens and hardened in the laboratory, under standard curing conditions, when applied to real substrates subjected to real climatic conditions, will not acquire equal characteristics. Thus, in order to choose a mortar more rigorously, it is very important to predict the behaviour of the mortar after application to the substrate.

With the objective, substrate, using the project funded is under

The aim is to cornp

specimens with the char necessary to apply the mortars to the substrates
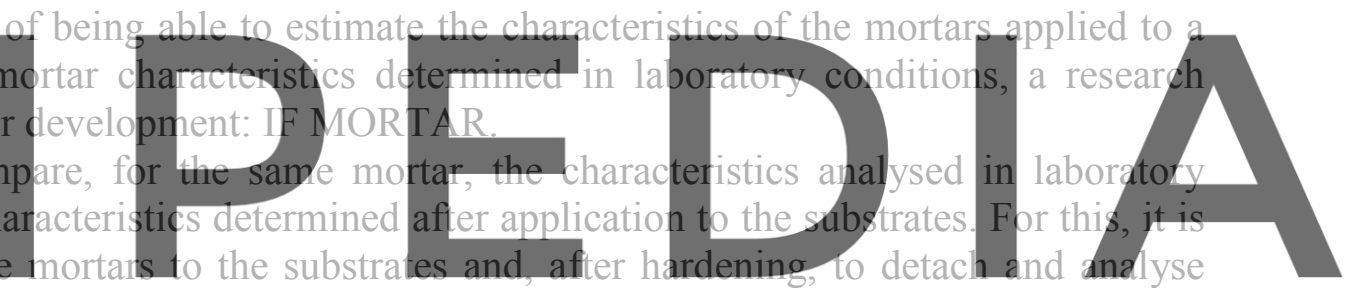

them. To facilitate the detachment of these mortars, a fiberglass grid has been introduced

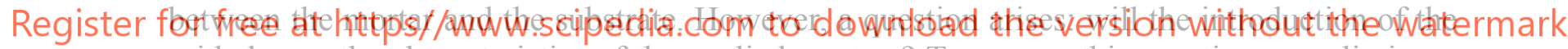
grid change the characteristics of the applied mortars? To answer this question, a preliminary experimental campaign was carried out, comparing the characteristics of the mortars applied to the substrates, with and without the application of the grid. Until now only two prescribe mortars were analysed, but the intention is to also analyse design mortars.

\section{Experimental Campaign}

\subsection{Introduction}

The experimental campaign developed aimed to analyse the behaviour of cement and hydraulic lime mortars applied to hollow ceramic brick substrates, in two different conditions: with and without the introduction of a fiberglass grid between the mortar and the substrate.

For this, a fiberglass grid was applied to half of the hollow brick substrates. Then, all the brick substrates were moistened and a $1.5 \mathrm{~cm}$ mortar layer was applied (Figure 1).

The following mortars were selected for the experimental campaign:

- Cement mortar, with a 1:4 cement to sand ratio, by volume;

- Hydraulic lime mortar, with a 1:3 lime to sand ratio, by volume. 
Both mortars were formulated in the laboratory.
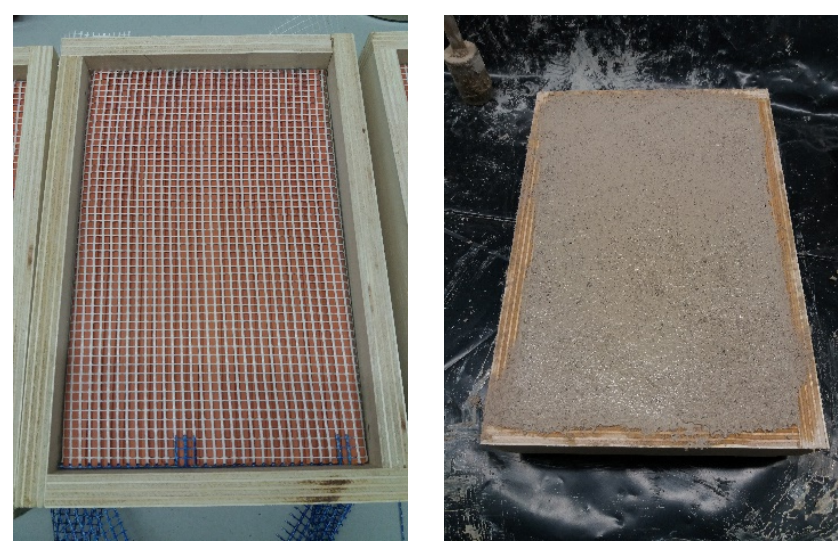

Figure 1. Application of the mortar to the substrate.

\subsection{Specimens and Tests}

The experimental campaign began with the execution of 40x40x160 mm3 prismatic specimens, for the determination of the bulk density, open porosity (NP EN 1936:2008), capillary water absorption (ISO 15148:2002) and compressive strength (EN 1015-11:1999), and cylindrical specimens (100 $\mathrm{mm}$ diameter and $15 \mathrm{~mm}$ thickness) for the determination of water vapour permeability (NP EN 1015-19:2008 and YSO 12572:2016) (Figure 2).
After the detachment of all mortars firom the substrates, specimens of appropriate dimension

After the detachment of all mortars fitom the substrates, specimens of appropriate dimensions
or the respective tests were cut. Given the thickness of the applied mortars $(1.5 \mathrm{~cm})$, it was no possible to obtain specimens with the exact dimensions indicated in the standards. Therefore

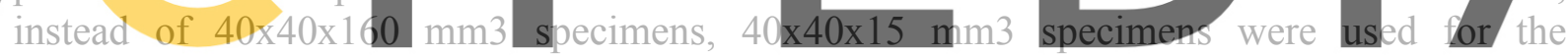
determination of bulk density, open porosity, capillary water absorption and compressive

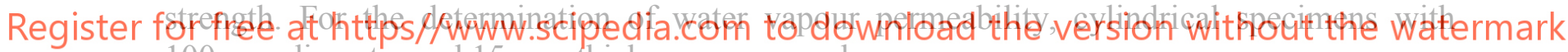
$100 \mathrm{~mm}$ diameter and $15 \mathrm{~mm}$ thickness were used.

After the execution of the laboratory specimens and application of the mortar layer on the substrates, all specimens were subjected to the following standard curing conditions: $20^{\circ} \mathrm{C}$ and $95 \% \mathrm{RH}$, for 7 days, and $20^{\circ} \mathrm{C}$ and $65 \% \mathrm{RH}$, for another 21 days.
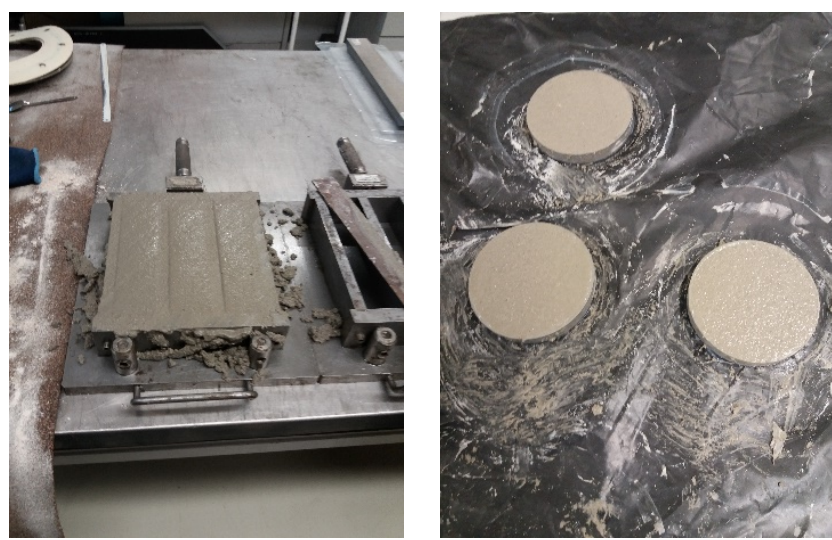

Figure 2. Test specimens. 
The results of the tests carried out are presented and commented in the following section. Even though the main objective is to compare the behaviour of the mortars applied to the substrate, the results obtained for the mortars hardened in the laboratory moulds are also presented.

\subsection{Presentation and Analysis of Results}

\subsubsection{Bulk density and open porosity}

The determination of the bulk density by the geometric method, which translates the simple direct relationship between the dry mass of a specimen and its apparent volume (volume limited by the outer surface of the specimens, including all voids) and the determination of the open porosity, which represents the relationship between the open pores volume and the apparent volume of the specimen, was conducted according to the standard. Figures 3 and 4 show the medium values and standard deviation obtained for bulk density and open porosity, respectively, for the specimens hardened in the moulds and for the specimens hardened on the substrates (with and without grid). It can be seen that the open porosity of the mortars decreased and the bulk density increased, after application to the substrates, as was expected.

When comparing the results of the mortars applied with the grid with those of the mortars applied without grid, it can be seen that they are very similar, i.e. the presence of the grid does not affect the results obtained.

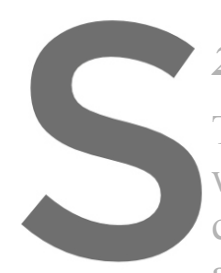
2.3.2 Capillary water absorption
The water absorption coefficient gives an indication of the water absorption capacity of a mortar
when placed in contact with a water film. The results obtained for the water absorption
coefficient, for all the mortars, are presented in Figure 5 . Once again, it can be scen that the
application of the mortars to the substrate changed this parameter, causing it to decrease. It is
also possible to observe that the difference between the results corresponding to the two

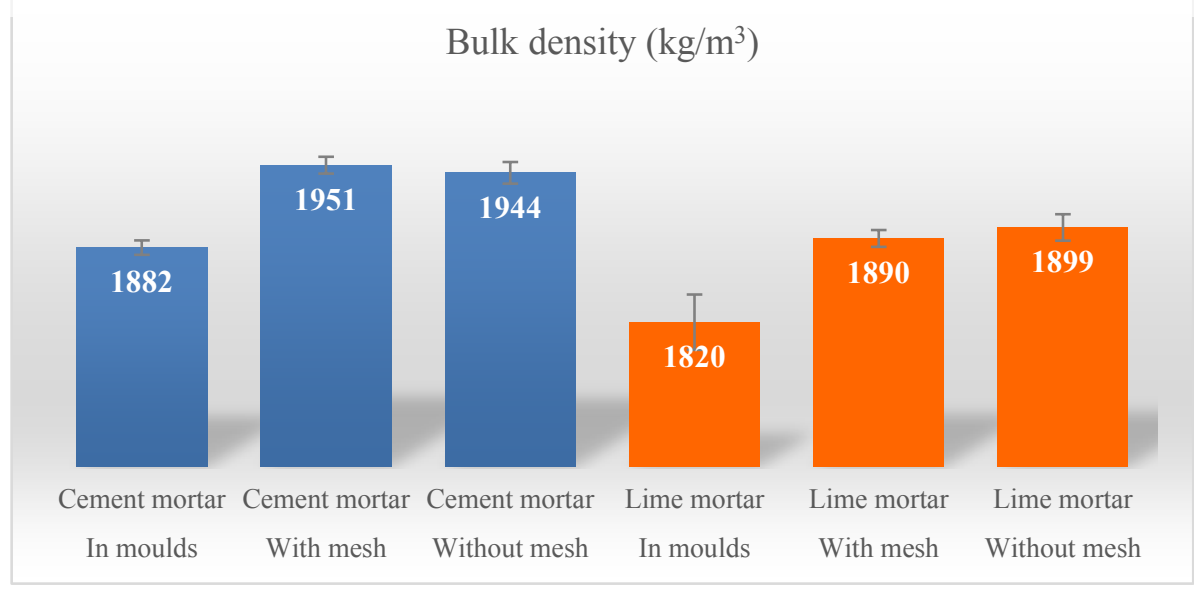

Figure 3. Bulk density. 


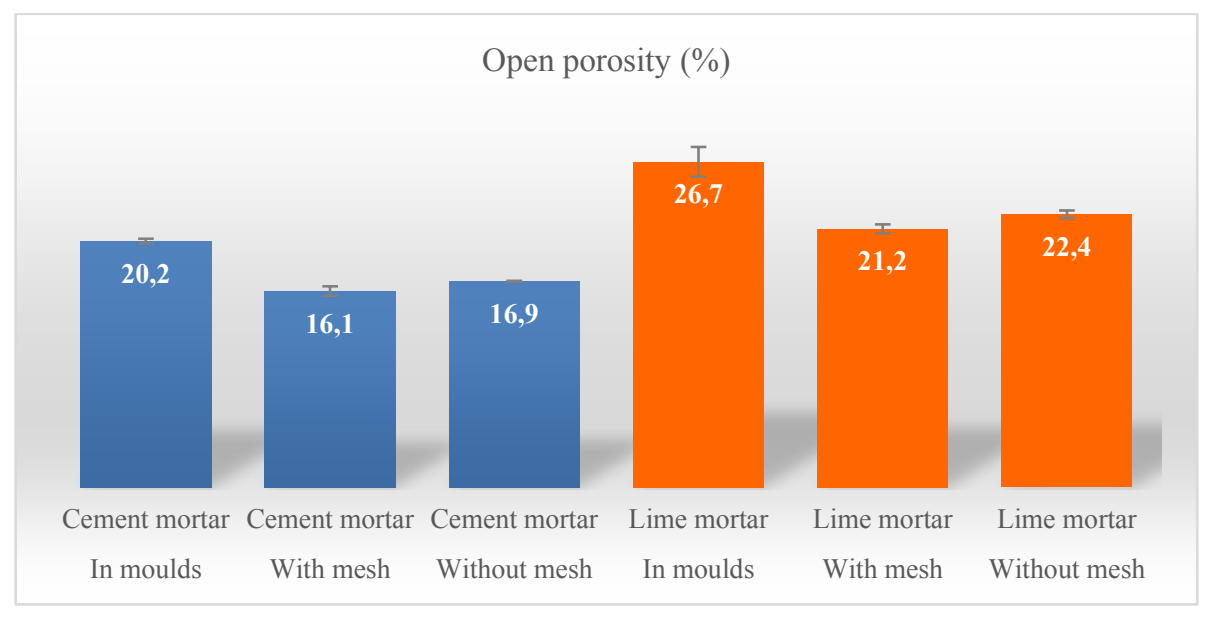

Figure 4. Onen porosity.

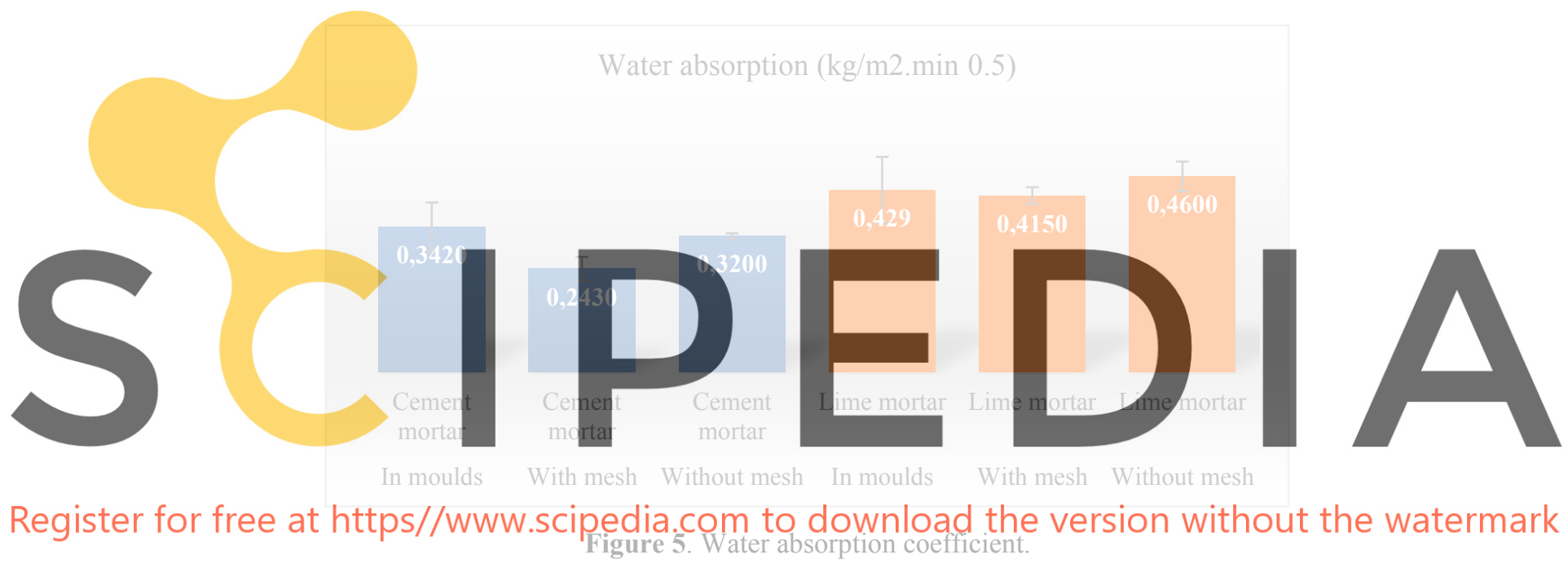

\subsubsection{Water vapour permeability}

The water vapour permeability coefficient, which reflects the ability of a material to be traversed by water vapour, was determined using the wet cup method.

Figure 6 shows the water vapour permeability coefficient results obtained for all the mortars.

The application of the cement mortar to the substrate led to a decrease in its water vapour permeability, while the application of the hydraulic lime mortar led to an increase of this parameter. In the case of the cement mortar applied to the substrate without grid, it was not possible to detach specimens for this test due to the high cohesion of the mortar to the substrate. For the hydraulic lime mortar, it was verified, once again, that the difference between the results of the detached specimens with and without grid were not significant. 


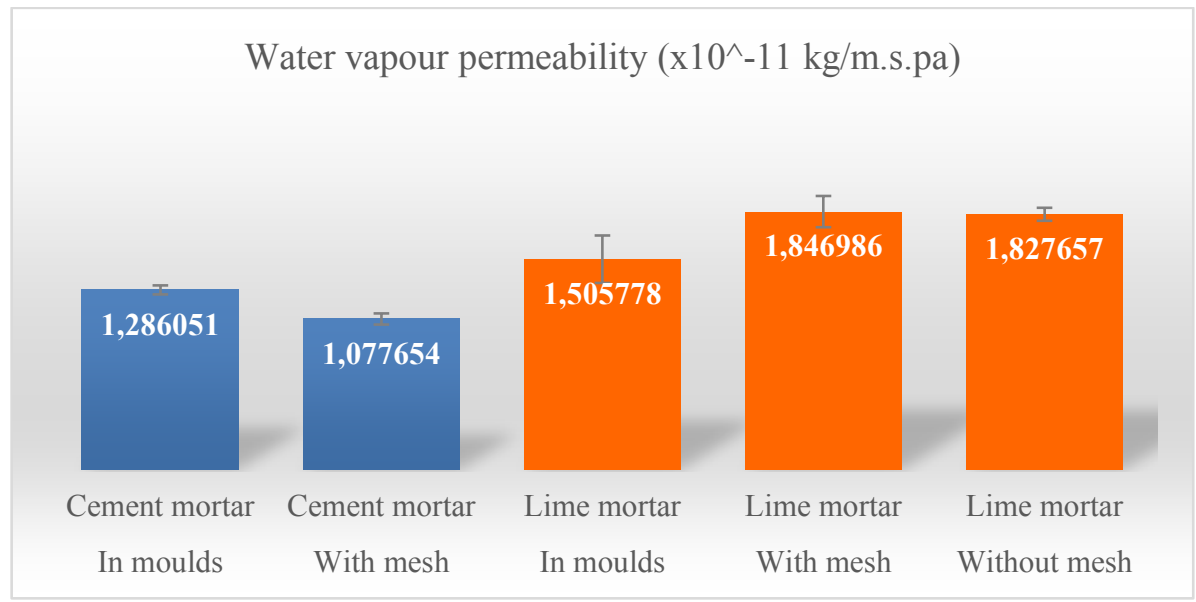

Figure 6. Water vanour nermeability.

\subsubsection{Compressive strength}

As it is not possible to cut specimens of sufficient size for the flexural test from the mortar layer applied to the substrates, only the results obtained for the compressive strength are presented here. The compressive strength is obtained by applying a compressive force (until failure) centred on the application area of $40 \times 40 \mathrm{~mm}^{2}$.

The compressive surength was detemined on the mortars hardened in the laboratory mould a Figure 7 presents the results obtained. It can be increased this property and that the introduction of results

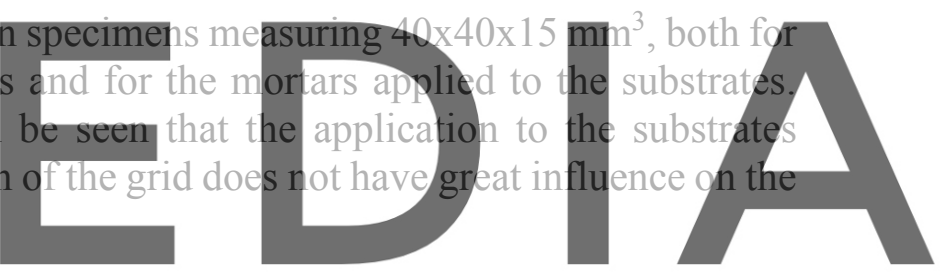

Register for free at https//www.scipedia.com to download the version without the watermark

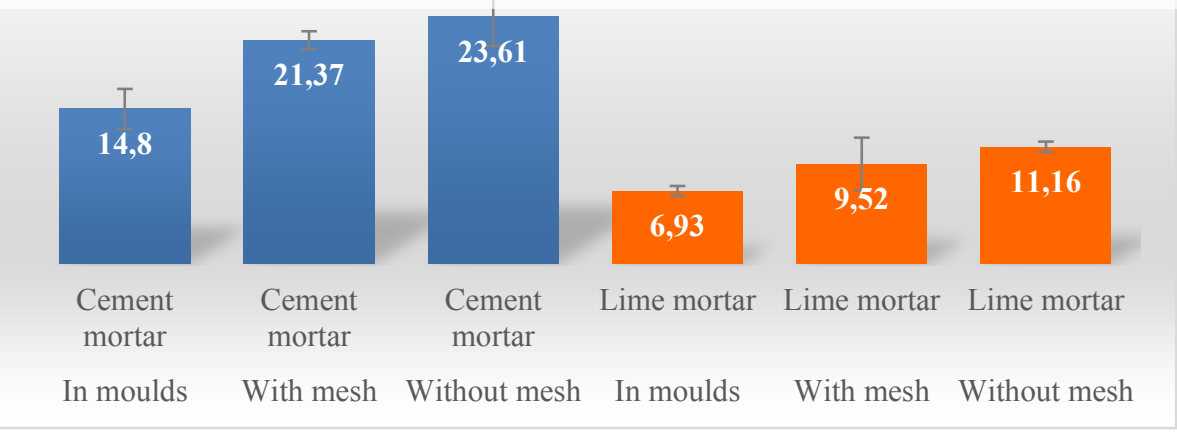

Figure 7. Compressive strength.

\section{Conclusions}

In order to choose a mortar in a more sustained way, regardless of its intended purpose, it is essential to know its behaviour, i.e. to know all its properties. These properties are determined 
on mortars hardened in moulds, in the laboratory, in accordance with the applicable standards.

The mortar in service, i.e. after application to the substrate, will acquire different properties from those determined in the laboratory, because the application conditions, interface characteristics, curing conditions, etc., are different from those considered in the laboratory.

To have knowledge of the in-service characteristics of mortars, it is necessary to apply them to the substrates, wait for them to harden, detach them from the substrates and, finally, analyse them.

Mortars are applied to the substrate in the plastic state and, when hardened, will adhere to it. The greater their adherence to the substrate, the more difficult their detachment will be. To facilitate this detachment, a grid can be introduced between the substrate and the mortar, but it is important to know whether this grid will affect the final properties of the mortar. The main objective of this work was thus to analyse the influence of the presence of a fiberglass grid, placed between the mortar and the substrate, on the properties of the applied mortars.

The experimental campaign conducted, which included the analysis of the influence of the presence of the fiberglass grid in the behaviour of cement and hydraulic lime mortars, concluded that the properties of the mortars do not change significantly due to the presence of this grid.

In fact, it was observed that the presence of the gird caused a slight increase in open porosity which also slightly increased water absorption and vapour permeability.

Although it was not the main objective of this work, the behaviour of the two mortars moulded in the laboratory moulds was also analysed and compared with the behaviour of the
mortars applied to the brick support. Qbserving the obtained results, it was possible to conclude that the application of th decrease of the open po The water absorption coefficient also decreaser expected because when the mortar of the fluid which is a porous material, part of its mixing water with the finer particles dissolved are

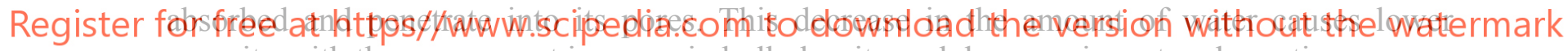
porosity with the consequent increase in bulk density and decrease in water absorption.

\section{Acknowledgements}

The work presented was carried out within the framework of the IF MORTAR project (POCI-01-0145-FEDER032223/PTDC/ECI-EGC/32223/2017,), within the scope of the Portugal 2020 program, financed by FEDER through the POCI program. The funding provided is kindly acknowledged. The authors also thank CERIS and CERENA, research units from IST.

\section{ORCID}

Isabel Torres: http://orcid.org/0000-0002-0515-1743

Inês Flores-Colen: http://orcid.org/0000-0003-4038-6748

Rafael Travincas Pinto: http://orcid.org/0000-0002-9059-1232

Dora Silveira: http://orcid.org/0000-0002-0063-2556

\section{References}

CEN (European Committee for Standardization). (1999). Methods of test for mortar for masonry. Part 11: Determination of flexural and compressive strength of hardened mortar. EN 1015-11. Brussels, Belgium: CEN. 
CEN (European Committee for Standardization). (1998). Methods of test for mortar for masonry. Part 19: Determination of water vapour permeability of hardened rendering and plastering mortars. EN 1015-19. Brussels, Belgium: CEN.

CEN (European Committee for Standardization). (2001). Hygrothermal performance of building materials and products-Determination of water vapour transmission properties. EN ISO 12572. Brussels, Belgium: CEN.

CEN (European Committee for Standardization). (2002). Methods of test for mortar for masonry. Determination of water absorption coefficient due to capillary action of hardened mortar. EN 1015-18. Brussels, Belgium: CEN.

CEN (European Committee for Standardization). (2006). Natural stone test methods. Determination of real density and apparent density, and of total and open porosity. EN 1936. Brussels, Belgium: CEN.

CEN (European Committee for Standardization). (1998). Methods of test for mortar for masonry. Part 2: Bulk samplingof mortars and preparation of test mortars. EN 1015-2. Brussels, Belgium: CEN.

Moropoulou, A., A. Bakolas, and K. Bisbikou. (2000). Physico-chemical adhesion and cohesion bonds in joint mortars imparting durability to the historic structures. Constr. Build. Mater. 14 (1): 35-46. https://doi.org/10.1016/S0950-0618(99)00045-8.

Silva, C. M., Flores-Colen, I. and Gaspar, S. (2013). Numerical analysis of renders' adhesión using an interface model, Construction and Building Materials, 2013, 38, 292-305
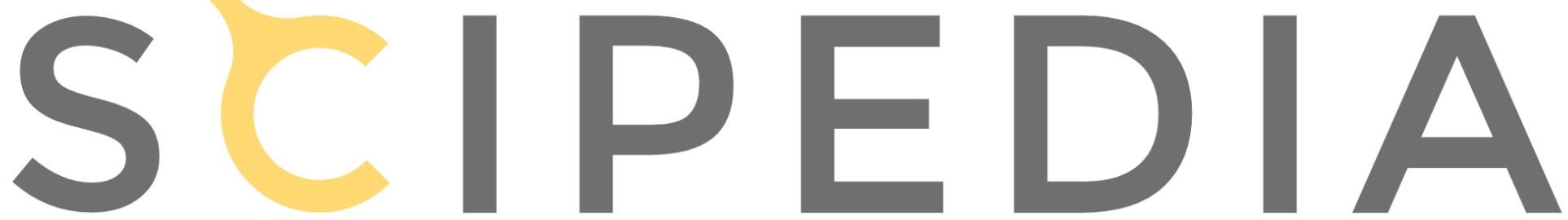

Register for free at https//www.scipedia.com to download the version without the watermark 